\title{
Arbor
}

\section{Aspectos jurídico-privados del fenómeno comunitario. Diversas situaciones de cotitularidad de bienes y derechos}

\section{Carolina del Carmen Castillo Martínez}

Arbor CLXV, 652 (Abril 2000), 613-637 pp.

\section{Consideración general}

El debate suscitado por el fenómeno comunitario puede analizarse desde muy variadas y heterogéneas vertientes. Así, partiendo de la perspectiva de la organización social de la comunidad política, el debate filosófico surgido en torno al fenómeno del comunitarismo viene ocupando ampliamente, en sus más diversas manifestaciones, a los estudiosos de la disciplina denominada Filosofía del Derecho. Desde esta óptica, en la etapa más reciente algunos autores se han ocupado básicamente de caracterizar el liberalismo político, esto es, la concepción rival de la comunitarista en el pensamiento contemporáneo. Tal es el caso de ACKER$\mathrm{MAN}^{1}$, quien realiza un análisis comparativo entre su propia concepción del liberalismo (la denominada perspectiva dialógica que desarrolla en su Social Justice in the Liberal State) y la de J. RAWLS, considerando a partir del análisis del último libro de RAWLS (Political Liberalism) que la nueva concepción no es consistente con la que se encuentra en $A$ Theory of Justice, pero aplaudiendo el marco general que aquél propone para el liberalismo político y que se condensa en seis principios que, esencialmente, vendrían a expresar objetivos presentes en la propia concepción de ACKERMAN, y concluyendo que el debate contemporáneo entre los «liberales» y los «comunitaristas» se basa en una falsa dicotomía pues, según señala «los liberales políticos no buscan fundar los derechos directamente sobre alguna noción de individualismo abstracto, sea kan- 
tiano o de otro tipo. Su apelación fundamental es a la comunidad, aunque a una comunidad de un tipo especial: una en la que sus miembros respetan los profundos desacuerdos de cada uno de los otros, pero estando dispuestos a trabajar con ellos para construir una forma de razón pública que les unirá en un diálogo común que todos puedan compartir, a pesar de sus otras diferencias». Desde semejante prisma, también LAPORTA ha estudiado la contraposición entre el liberalismo y el comunitarismo, a propósito del problema del nacionalismo, para concluir que entre comunitarismo y nacionalismo existe "un claro parecido de familia», lo que le lleva a sugerir que «en la medida en que el nacionalismo pueda ser comprendido y justificado como algo que deriva de la lógica interna de una filosofía moral de tipo comunitarista, entonces algunos evidentes corolarios del nacionalismo y algunas de las experiencias históricas que ha desencadenado podrían ser objeto de esa comprensión y esa justificación; para destacar, " $a$ sensu contrario», que la buena sintonía existente entre el nacionalismo como proyecto político y el comunitarismo como teoría moral le lleva también a pensar que la filosofía moral liberal no suministra puntos de apoyo idóneos para justificar el nacionalismo ${ }^{2}$. Otros pensadores entienden que el rasgo fundamental de la doctrina comunitarista es la idea de que «los individuos conciben su identidad como definida - aunque sea parcialmente - por la comunidad de la que son parte», mientras que el liberalismo concibe a las personas como «seres individuales, cuyo bienestar es independiente de entidades tales como la familia, la comunidad, la tribu o la nación", entendiendo a partir de aquí que la concesión de los llamados «derechos comunitarios no constituye la solución para proteger a las minorías amenazadas en su propia existencia: los derechos comunitarios no son sino el modo en que se describe cierta restricción de los derechos individuales; por eso, si el grupo protegido es una minoría, los derechos comunitarios son disfraces que encubren la restricción de los derechos individuales de la mayoría, de tal modo que resulta que el liberalismo puede ofrecer una mejor solución para este problema, si bien la misma no deja de tener defecto» ${ }^{3}$. La opinión sobre las teorías comunitaristas que ofrece RIVERA ${ }^{4}$ no es mucho más favorable que las anteriores, diferenciando, en la teoría moral liberal, dos niveles: el metaético y el normativo o sustantivo; en el primer nivel, lo que caracteriza al liberalismo es la defensa de la tesis de la universalidad y de la neutralidad; en el segundo, la aceptación de «los derechos individuales, la tolerancia religiosa, la libre expresión, las normas de justicia distributiva, el valor de la autonomía individual, la democracia liberal, etc ...», surgiendo así dos tipos de comunitarismo: el comunitarismo débil que critica los presupuestos metaéticos del liberalismo, pero considera 
Aspectos jurídico-privados del fenómeno comunitario...

compatible ser comunitarista en ese plano y ser liberal en el otro (en el plano sustantivo), y el comunitarismo fuerte que critica el liberalismo en dos niveles, llevando ambas concepciones a posiciones paradójicas, pues -para sostenerlas es preciso adherirse, en el primer caso, a la tesis universalista y, en el segundo, a la neutralista, si bien la paradoja podría resolverse si se abandona la tesis universalista, si bien entonces ya no estaríamos frente a una teoría genuinamente comunitarista. Sirva cuanto antecede como botón de muestra que no hace sino poner de manifiesto la multiplicidad de cuestiones que el debate en torno al comunitarismo provoca desde las diversas disciplinas a partir de las cuales se acometa su conocimiento. El propósito de este trabajo se centra en el análisis, necesariamente breve, de las distintas expresiones que, en el orden jurídicoprivado, presenta la organización de cotitularidades recayentes en una pluralidad de personas determinadas, como fenómeno contrapuesto a la titularidad individual, de una persona (física o jurídica), sobre bienes o derechos de naturaleza privada.

La alternativa suscitada por la dicotomía que contrapone la defensa de lo estrictamente individual frente a lo colectivo se traslada al Derecho privado, ámbito en el que la plasmación del interés exclusivamente individual como contrapuesto al colectivo se traduce en diversas formas de articulación de las titularidades individuales, como exclusivas de la persona física o jurídica (sujeto de derecho), frente a titularidades colectivas, supuestos en los que la atribución de poderes concretos sobre las cosas o los derechos se realiza no de manera exclusiva y excluyente sobre un sujeto individual sino sobre un titular colectivo o plural. Como he señalado, el análisis de los diversos aspectos del fenómeno comunitarista o colectivo en el ámbito del Derecho privado, y más precisamente en la esfera del Derecho civil, constituye el objeto de exposición de las siguientes páginas que tratan de ofrecer un panorama de las posibles manifestaciones que en nuestro ordenamiento jurídico-civil plantean las diversas situaciones de cotitularidad de bienes y derechos. Desde la consideración precedente, y al margen de explicaciones dogmáticas acerca de la naturaleza jurídica de la comunidad de bienes, paradigmáticamente entendida como situación de cotitularidad de bienes y derechos, que han determinado un complejo debate doctrinal que ahora no interesa reproducir ${ }^{5}$, estas páginas pretenden concluir la relevancia que en el orden privado continúan teniendo determinadas formas de organización plural de los sujetos individuales, a través de la exposición sintética de las distintas figuras que posibilitan la organización de un sujeto plural cuya regulación supedita el. interés individual y excluyente a otro que lo supera. 


\section{Situaciones de cotitularidad de bienes y derechos}

\section{La comunidad, en general}

\section{a) Concepto y fuentes}

A tenor de lo dispuesto en el artículo 392 del Código civil, «hay comunidad cuando la propiedad de una cosa o de un derecho pertenece proindiviso $a$ varias personas». $\mathrm{Al}$ respecto, conviene poner de relieve que debe entenderse «la propiedad de una cosa o la titularidad de un derecho en cosa ajena», pues, por definición, el derecho en cosa ajena no es objeto de propie$\operatorname{dad}^{6}$. En esta categoría de comunidad, definida por nuestro Código civil, resulta que el derecho de cada partícipe es cualitativamente igual al otro, de manera que todos son, a la vez, propietarios, usufructuarios, enfitéutas ..., y todos tienen un derecho de la misma naturaleza, aunque su titularidad les pueda pertenecer en proporción distinta a cada uno de ellos. Diversamente, no constituyen comunidad, en el sentido indicado, aquellas situaciones de concurrencia de varios derechos que componen e integran la propiedad total o completa de una cosa, como por ejemplo el usufructo y la nuda propiedad; tampoco la «propiedad» dividida en aprovechamientos independientes. La comunidad de bienes puede tener su orígen en la voluntad privada (un pacto) o bien derivarse de un hecho que por disposición legal determina su constitución (una sucesión hereditaria). En todo caso, cada comunidad se gobierna, en primer lugar, por las normas imperativas que le sean aplicables según su naturaleza; y, seguidamente, por las reglas establecidas por los partícipes, si bien éstas, en determinados supuestos, únicamente pueden ser establecidas ajustándose a determinadas formas (así, por ejemplo, en la comunidad conyugal, el otorgamiento de capitulaciones matrimoniales). Salvo lo anterior, la voluntad individual de los partícipes resulta soberana para convenir las reglas reguladoras de la pluralidad de derechos iguales sobre una misma cosa, de tal manera que podrá convenirse, por ejemplo, que sea uno solo de los comuneros el que ejerza funciones de administración del bien común, o bien el uso exclusivo del mismo por parte de alguno de ellos ..., incluso en el supuesto de que dichos pactos sean contrarios a lo dispuesto (supletoriamente) por la ley (cfr. art. $392.2^{\circ}$ del C.C).

b) Comunidad y sociedad

Inicialmente conviene señalar que los artículos 392 y siguientes del Código civil encuentran aplicación a la comunidad, entendida como si- 
Aspectos jurídico-privados del fenómeno comunitario...

tuación de pertenencia plural de un bien o conjunto de bienes, y no a la sociedad, configurada como organización de personas que actúan con un proposito de lucro. Por ello, desde el punto de vista jurídico, resulta esencial la distinción entre comunidad y sociedad, que puede perfilarse desde diversos puntos de vista. Así, por el orígen, como indicaban los romanos, societatem contrahimus, in comunionem autem incidimus, es decir, que a la comunidad podemos llegar a pertenecer incluso faltando la intervención de nuestra voluntad. También se diferencian por el destino de la sociedad a la obtención ganancias, expresamente establecido por la voluntad de los socios. Asimismo, por la obligación de los socios de cooperar a la obtención de las ganancias (art. 1665 del C.C), frente a una posible inercia del comunero y su carencia de obligaciones de gestión y cooperación, de tal manera que lo decisivo en la sociedad no es tener sino más bien hacer algo en común. Reflejo de lo antedicho es la conocida Sentencia del Tribunal Supremo de 15 de octubre de 1940, en la que se declara que si en nuestro Derecho positivo se ofrecen a veces dificultades al tratar de fijar la línea divisoria entre comunidad de bienes y contrato de sociedad, la doctrina científica señala como nota fundamental de diferenciación, además del orígen o fuente de que surgen, no siempre uniforme, la finalidad de los interesados: lucro común partible en la sociedad y mera conservación y aprovechamiento en la comunidad ${ }^{7}$.

\section{La copropiedad como modelo regulado por el Código civil}

Nuestro Código civil regula la comunidad de derechos sobre bienes a través de la que, sin duda, constituye su más importante especie: la propiedad de varios titulares sobre una misma cosa o copropiedad. En el modelo regulado por el Código, el condueño o copropietario tiene una participación alícuota sobre la cosa (entiéndase sobre su propiedad), expresada numéricamente, de tal manera que el derecho del titular parciario se cuantifica mediante la expresión de una cuota, constitutiva de la manifestación numérica del contenido de su participación (un tercio, un quinto, una doceava parte ...). La copropiedad o condominio no es sino la comunidad aplicada al derecho de dominio, constituyendo la más importante modalidad de comunidad de bienes y derechos, a la que implícitamente se refieren los preceptos del Código civil reguladores de la comunidad de bienes. Partiendo del régimen legal ofrecido por nuestro Código civil, los aspectos más relevantes de la copropiedad podrían resumirse en lo que seguidamente queda expuesto. 
En principio conviene señalar que la cuota constituye la medida del derecho del partícipe en todos aquellos aspectos en los que el aprovechamiento económico de la cosa es cuantificable, presumiéndose iguales, «mientras no se pruebe lo contrario, las porciones correspondientes a los partícipes en la comunidad» (art. $393.2^{\circ}$ del C.C). La cuota ofrece la medida del derecho de cada uno al disfrute de la cosa, de su participación en los frutos o rentas que produce (art. 393 del C.C), y únicamente cuando en algún aspecto concreto la cuantificación resulta imposible o no se ha verificado, en la duda, todos los partícipes y comuneros tienen derecho al aprovechamiento con arreglo a sus posibilidades. Este y no otro parece ser el sentido del artículo 394 del Código, según el cual, «cada partícipe podrá servirse de las cosas comunes, siempre que disponga de ellas conforme a su destino y de manera que no perjudique el interés de la comunidad, ni impida a los copartícipes utilizarlas según su derecho». No obstante, la referida igualdad de oportunidades de aprovechamiento debe entenderse como circunstancial, ya que bastaría el acuerdo del conjunto de los condueños para que cada uno de ellos participara en el resultado económico de dicho aprovechamiento en proporción a su cuota; de este modo resulta que el artículo 394 no da derecho a un aprovechamiento igual, sino más bien a que un partícipe no impida a los demás extraer de la cosa todas las utilidades "según su derecho», y por tanto en proporción a su cuota, de conformidad con la regla de principio del artículo 393 del Código. En cuanto a la esfera de actuación colectiva de los comuneros, se circunscribe ésta a la administración de la cosa común pues, a tenor del artículo $398.1^{\circ}$ a $3^{\circ}$ del Código civil, "para la administración y mejor disfrute de la cosa común, serán obligatorios los acuerdos de la mayoría de los partícipes. No habrá mayoría sino cuando el acuerdo esté tomado por los partícipes que representen la mayor cantidad de los intereses que constituyan el ob'to de la comunidad. - Si no resultare mayoría, o el acuerdo de ésta fue-

gravemente perjudicial a los interesados en la cosa común, el Juez pro-crá, a instancia de parte, lo que corresponda, incluso nombrar un administrador». $\mathrm{Al}$ respecto, por actos de administración cabría entender aquéllos que regulan el disfrute de la cosa sin alterar su sustancia; básicamente, son los que se refieren al aprovechamiento y conservación de la cosa; a la producción por la misma de frutos o rentas, a prepararla para un mejor disfrute sin modificaciones o alteraciones sustanciales, ..., contraponiéndose, de manera general, a aquellos actos que implican la enajenación de la cosa, en todo o en parte (una compraventa), o la imposición de un gravamen (una hipoteca), o bien una alteración fáctica sustancial ${ }^{8}$.

En cuanto a la participación en las cargas y gastos, según dispone el artículo $393.1^{\circ}$, «el concurso de los partícipes ... en las cargas será pro- 
Aspectos jurídico-privados del fenómeno comunitario...

porcional a sus respectivas cuotas» ${ }^{9}$, precisando el artículo 395 que «todo propietario tendrá derecho para obligar a los partícipes a contribuir a los gastos de conservación de la cosa o derecho común». Conviene precisar que el conjunto de los comuneros carece de personalidad jurídica, de modo que, en principio, debería organizarse como una pluralidad de sujetos individuales; sin embargo, la comunidad es algo más que una pluralidad de individuos, pues tiene un principio de organización, de tal manera que no sólo puede tomar decisiones vinculantes por unanimidad sino también, respecto a la gestión de la cosa común, por mayoría, con el resultado, al que no se llega en la persona jurídica, de que el condueño puede quedar indirecta o mediatamente comprometido por determinadas deudas que no haya contraído personalmente ni a través de su representante voluntario. Parece indudable que las deudas contraídas por un comunero respecto de la comunidad obligan al resto, aunque no hayan prestado su consentimiento, siempre y cuando afecten a la conservación de la cosa común. En un sentido diverso, sería cuestionable el que un condueño pudiera resultar obligado por unos gastos originados por una simple mejora del bien acordada contra su voluntad.

Con referencia a la facultad de disposición sobre la cosa común, conviene señalar que de la misma se puede disponer bien alterando sustancialmente su esencia o bien transmitiendo o enajenando, total o parcialmente, el poder jurídico que se tiene sobre ella. Respecto de la primera forma, el artículo 397 establece que «ninguno de los condueños podrá, sin consentimiento de los demás, hacer alteraciones en la cosa común, aunque de ellas pudieran resultar ventajas para todos", pues las variaciones sustanciales exigen el consentimiento de todos los partícipes, bastando el de la mayoría cuando la alteración no afecte a la sustancia de la cosa y se realice sólo para su mejor disfrute. En cuanto a la enajenación del bien sólo se podrá verificar cuando en ello convengan todos los que en el mismo tengan parte, sin excepción (cfr., para las servidumbres, el art. 597 del C.C), resultando, en este supuesto, que la referida disposición total no resulta de la suma de las disposiciones de cada partícipe sobre su respectiva participación, tal y como pone de manifiesto el hecho de que ninguno, por sí solo, puede gravar la finca indivisa con una servidumbre, pero sí conjuntamente. De manera que no es que cada uno tenga una parte en la facultad de disposición, que como tal es jurídicamente indivisible, sino únicamente un derecho a concurrir para formar la voluntad común o, diversamente, en el supuesto de que no se concurra, a impedir que dicho consentimiento común se forme.

Finalmente, en cuanto a la división de la cosa común como modo de extinción de la situación de comunidad, hay que señalar que ya el Dere- 


\section{Carolina del Carmen Castillo Martínez}

cho romano consideró la indivisión como una situación indeseable, por consiguiente transitoria, de la que cada comunero podía salir por voluntad propia. Esta es la regla tradicional consagrada en todas las legislaciones. En nuestro Código, sea la cosa común divisible o no, la comunidad ordinaria es siempre y necesariamente divisible. De conformidad con lo prevenido en el artículo $400.1^{\circ}$, «ningún copropietario estará obligado a permanecer en la comunidad. Cada uno de ellos podrá pedir en cualquier momento que se divida la cosa común». Además, la acción para pedir la división es imprescriptible (art. 1965 del C.C). Ni siquiera por pacto o convenio entre los comuneros se puede prorrogar indefinidamente o durante un período prolongado la división; así, como dispone el artículo $400.2^{\circ}$, «será válido el pacto de conservar la cosa indivisa por tiempo determinado, que no exceda de diez años. Este plazo podrá prorrogarse por nueva convención ${ }^{10}$. La apuntada es la única excepción admitida legalmente al principio de libre disolubilidad del consorcio, pudiendo realizarse la división de la cosa común por los mismos interesados o por árbitros o amigables componedores nombrados a voluntad de los partícipes, resultando, en éste útimo caso, la obligación de formar partes proporcionadas al derecho de cada uno, evitando en cuanto sea posible los suplementos a metático (art. 402 del C.C). En todo caso, siempre le quedará al comunero el recurso de acudir a la división judicial, debiendo el demandante en tal supuesto presentar alguna propuesta de partición, pues ni el procedimiento declarativo ordinario es el apto para verificarla ni el órgano jurisdiccional tiene cualificación ni oportunidad procesal para hacerlo ni mandarlo hacer. En definitiva, la partición legalmente hecha confiere a cada antiguo partícipe la propiedad exclusiva de los bienes que le hayan sido adjudicados (art. 1068 del C.C), de modo que, mediante la partición, el anterior derecho de cuota, concurrente con otros cualitativamente iguales sobre una cosa común, se transforma en titularidad individual, generalmente exclusiva, sobre una parte de la cosa.

\section{Comunidades de tipo «romano» diversas de la copropiedad}

Ciertamente la pluralidad de sujetos titulares anteriormente señalada puede predicarse en relación con cualquier derecho real. A tal situación se refiere el artículo 531 de nuestro Código civil, al permitir la constitución de servidumbres en favor de «una o más personas, o de una comunidad». En estos supuestos, con carácter general, se aplicarán las normas de la copropiedad o condominio, si bien ajustada a la concreta naturaleza del derecho real de que se trate. No obstante, en algunos casos, 
Aspectos jurídico-privados del fenómeno comunitario...

el Código civil contiene normas específicas. Así, para el usufructo, el artículo 521 dispone que el usufructo constituido en provecho de varias personas vivas al tiempo de su constitución, no se extinguirá hasta la muerte de la última que sobreviviere, de manera que la porción que deja vacante cada difunto acrece a los que sobreviven; y el artículo 490, relativo al usufructo de una participación indivisa, otorga a su titular el derecho a ejercer todos los derechos que correspondan al propietario de ella referentes a la administración y a la percepción de frutos o intereses y, tras la división de la cosa, la parte concreta de ella adjudicada al titular de la porción usufructuada se subroga en lugar de la misma cuota indivisa y es objeto del mismo usufructo. Cuando el derecho real limitado es de garantía se produce una situación particular, ya que en el mismo no puede dejar de incidir el derecho de crédito del que el de garantía siempre es accesorio, de tal manera que, en virtud de dicha accesoriedad, y además porque no nos encontramos ante un derecho de goce, la forma de su ejercicio no será la prevista en los artículos 393 y siguientes del Código civil, sino la que emane de la cualidad solidaria o mancomunada del crédito. Así, con precisa referencia a la garantía inmobiliaria por excelencia cual es el derecho real de hipoteca, si el crédito asegurado es solidario cada acreedor podrá ejercitar sus derechos respecto de aquélla, produciéndose en tal situación, excepcionalmente, respecto de dicho derecho real de garantía, un resultado que no es alcanzable en el ámbito de la propiedad; diversamente, si el crédito principal es mancomunado, la hipoteca únicamente podrá hacerse efectiva conjuntamente por los acreedores, aplicándose a los actos de conservación y administración las reglas de la copropiedad ordinaria, como sucede en el supuesto de la comunidad hereditaria.

\section{Coposesión}

En la hipótesis de que varios sujetos posean una cosa en común, a tenor de lo establecido en los artículos 445 y 450 del Código civil, nos encontramos ante un supuesto de coposesión. Al respecto, conviene la doctrina en que si dos personas poseen en común una cosa y ésta es indivisible la poseen juntos cada uno por el total, pues no cabe poseer en parte una cosa que, siendo indivisible, no es susceptible de posesión parcial, de manera que cada titular mantiene un contacto físico con la totalidad de la cosa que tiene efectos para él y para los otros cotitulares sin posibilidad de excluir a éstos. Cada uno de los coposeedores puede recurrir a la protección posesoria y en particular ejercitar interdictos contra 
cualquiera que perturbe su tenencia o le prive de ella, pero siempre actuando en interés de la colectividad, ya que no es un coposeedor solidario. Verdaderamente, cada condueño posee la cosa entera en virtud de su derecho de uso sobre toda ella pero sin que dicha posesión sea exclusiva ni excluyente, pudiendo quedar reducida a una posesión mediata, desprovista de contacto físico sobre la cosa si la misma, por acuerdo de la mayoría, se entrega a un poseedor inmediato. Por tanto se trata, incluso en el supuesto de ejercicio físico de la tenencia, de una influencia compartida que únicamente podrá ejercerse con plenitud por un sólo comunero si los otros rechazan compartir su ejercicio. Entonces el ejercicio de cada uno vale para todos, sin que esta posesión sirva para quien la ejerce como si fuera posesión exclusiva, ni pueda impedir el acceso de los otros partícipes a la cosa ni, mucho menos, usucapirla para el ejerciente. A tenor de lo dispuesto por el artículo 1933 del Código civil, la prescripción ganada por un copropietario o comunero aprovecha a los demás, de manera que cualquiera de los coposeedores puede usucapir en favor del colectivo al que pertenece. Para que no resulte así y adquiera la finca el coposeedor que realice los actos posesorios materiales, es preciso que éste invierta el título posesorio, comenzando a poseer individualmente mediante actos suficientemente públicos y significativos, y también que en tal cualidad posea el tiempo legalmente necesario para usucapir, y no únicamente la posción temporal que resta de posesión colectiva.

\section{El modelo de comunidad «germánico»}

a) Referencia a los modelos de comunidad: comunidad «romana» y comunidad «germánica»

Resulta frecuente entre los civilistas contraponer, en el estudio de las instituciones jurídicas, «lo romano» a «lo germánico». Tal comparación, para el Derecho castellano anterior al Código civil, contrapone la normativa de las Partidas y el Derecho romano a la del Fuero Viejo, el Fuero Real y los Fueros Municipales.. Siguiendo tal argumentación, la contraposición más extendida es la resultante de oponer el modelo de comunidad «romana», extraído de las Pandectas y finalmente regulado en nuestro Código civil en los precitados artículos 392 y siguientes, con el otro modelo "germánico» de comunidad, dotada ésta de una finalidad que cumplir, cuyos miembros se encuentran unidos entre sí por un vínculo personal, procediendo de acuerdo en el disfrute y la gestión de los bienes 
Aspectos jurídico-privados del fenómeno comunitario...

comunes, resultando su participación en la cosa común no enajenable y el contenido de la misma no expresado en partes alícuotas. Como señala CASTÁN TOBEÑAS, «en la comunidad o condominio de Derecho romano la cosa pertenece a los condóminos por partes intelectuales o cuotas (partes pro indiviso). En la comunidad de Derecho germánico —o sea, la llamada propiedad colectiva o en mano común ...- la cosa pertenece a la colectividad, sin ninguna división ideal de cuotas. En la primera cada comunero puede disponer de su cuota, mientras que en la segunda, no existiendo cuotas propiamente dichas, no existe la posibilidad de disponer o enajenar. En la comunidad romana, cada condueño tiene, para la realización de la cuota, la acción de división (actio communi dividundo), mientras que en la germánica no existe dicha acción, porque falta una participación específica y precisa» ${ }^{11}$.

Con acierto, a mi juicio, considera LACRUZ que en la comparación entre la comunidad romana y germánica se da un triple equívoco. En primer lugar, el anacronismo de poner en pie de igualdad dos ordenamientos jurídicos en etapas muy distintas de su desarrollo: un ordenamiento como el romano, en fase de avanzada madurez técnica y al servicio de un Estado y una sociedad muy evolucionados, y otros, los resumidos bajo el nombre de «Derecho germánico», en una etapa muy incipiente de economía familiar y tribal, operando en un medio social y político primitivo. En segundo lugar, la circunstancia de que no existe un «Derecho germánico", sino los ordenamientos, mal conocidos, de multitud de pueblos y tribus, de los cuales la doctrina extrapola unos rasgos más o menos comunes, de tal modo que acaso el resultado de la extrapolación no coincida con ninguna normativa histórica. Finalmente, como dato más grave, el hecho de que la comunidad germáni$c a$ que describen los autores, y más todavía la doctrina española, no es una comunidad concreta, regulada por algunas leyes concretas de algún concreto pueblo para una concreta ocasión, sino una síntesis arbitraria realizada sobre los ordenamientos jurídicos de muchos pueblos en diversas épocas y, además, asumiendo notas características de algunos tipos de comunidad - sobre todo de las familiares- que faltan, sin embargo, en otros. De tal manera que lo que propone la doctrina como «comunidad germánica» es una abstracción de un modelo teórico, pero no un instituto real y operante en un tiempo y lugar determinados ${ }^{12}$.

En todo caso, según la doctrina dominante, son dos ejemplos de comunidad "germánica» o en mano común recogidos por nuestro ordenamiento jurídico civil, la comunidad hereditaria y la comunidad conyugal, a las que seguidamente me refiero. 
b) Comunidad universal. Comunidad hereditaria y comunidad conyugal

Cuando son más de uno los herederos llamados a una sucesión, cada uno de ellos, en tanto la partición no se efectúe, no tiene un derecho concreto sobre ninguna de las cosas de la herencia, ya que se desconoce cuál de ellas le va a corresponder finalmente, sino sólo un derecho en el complejo hereditario, entendido éste como unidad más o menos circunstancial. La particularidad de la comunidad existente entre los sucesores de parte alícuota de un causante es que la parte correspondiente a cada heredero es transmisible libremente, pudiendo su titular, en consecuencia, venderla o donarla, contra el principio general subyacente en la denominada comunidad «germánica». Por otra parte, resulta que las normas aplicables a la administración y disposición de los bienes relictos son las de la copropiedad «romana» regulada en el Código civil. Pese a lo indicado, la razón de que a esta comunidad se la califique de «germánica» encuentra un motivo histórico, que radica en la idea extendida desde finales del siglo pasado, tanto en la jurisprudencia de nuestro Tribunal Supremo como en las resoluciones de la Dirección General de los Registros y del Notariado, según la cual en una herencia los bienes del causante constituyen una unidad cuyo destino primordial es responder por las deudas del causante o las del propio caudal hereditario, resultando posteriormente ser los sucesores quienes habrán de dividirlos entre sí. Desde tal consideración, el Tribunal Supremo ha declarado que durante «el período de división que precede a la partición hereditaria los herederos poseen el patrimonio del causante colectivamente, permaneciendo indeterminados los respectivos derechos» (Sentencia de 29 de enero de 1943), de manera que «no sólo la cuota hereditaria tiene un contenido inconcreto, sino que hay (en relación a los bienes) una indeterminación de sujetos cuya individualización no se produce hasta la liquidación del patrimonio» (Sentencia de 7 octubre de 1963), resultando que, hasta entonces «cada heredero sólo disfruta de una parte ideal de todos los bienes de la herencia» (Sentencia de 25 de noviembre de 1961), sin que ostente una titularidad ordinaria cualquiera sobre cada bien singular sino «un derecho abstracto sobre toda la herencia concebida como universum ius» (Sentencia de 21 de abril de 1971). En consecuencia, la Dirección General de los Registros y del Notariado, desde fin de siglo, no admite la inscripción en el Registro de cuotas partes de cada heredero singular sobre un inmueble indiviso, pues la comunidad hereditaria es universal, recayente sobre todo un patrimonio, de manera que la cuota la tiene el heredero, como expresión cuantitativa de su titularidad, sobre el conjunto de 
Aspectos jurídico-privados del fenómeno comunitario...

la herencia y no como una participación indivisa en todos y cada uno de los objetos singulares integrantes del caudal hereditario. En todo caso, conviene tener presente que la doctrina se muestra vacilante a la hora de fijar la naturaleza jurídica de esta especie de comunidad ${ }^{13}$.

Más cercana al modelo de la comunidad «germánica» se encuentra la comunidad conyugal, como, por ejemplo, la sociedad de gananciales. Tiene carácter personalísimo, es constituída para cumplir una finalidad concreta, y es indisoluble por voluntad de uno de los cónyuges (al respecto, conviene señalar que, hasta 1975, ni siquiera por la de ambos, según la regulación ofrecida por el Código civil). Las participaciones en la comunidad conyugal son intransferibles, de manera que, vigente la misma, ni el marido ni la mujer pueden enajenar su parte en la comunidad. Además, la comunidad conyugal se incrementa por la afluencia de las ganancias de los cónyuges, como sucede en la sociedad, gobernándose por un principio social, pues se dirige a sufragar las necesidades familiares sin que los beneficios obtenidos puedan repartirse antes de su disolución ${ }^{14}$.

c) Aprovechamientos comunales de pastos y leñas

Es tradición en muchas regiones y pueblos en los que los vecinos propietarios de ganado tienen el derecho de aprovechar las hierbas del término propio o vecino (alera foral en Aragón, pastos de facería en Navarra) que, en virtud de concesiones reales, de costumbre o de contrato se constituyan los aprovechamientos comunales de pastos y leñas. En anteriores etapas históricas el derecho a los bienes comunales pertenecía al común de vecinos; actualmente, en muchos lugares, ha pasado al Municipio, si bien los vecinos ganaderos conservan el disfrute de los pastos como un derecho del cual el Consejo no les podría privar ${ }^{15}$. En este sentido queda constituída una comunidad que conserva ciertos caracteres «germánicos»; así, los vecinos, en número indeterminado y variable, en ocasiones no tienen tasa en la utilización de los pastos por sus ganados, de tal manera que no concurren cuotas de disfrute; por otra parte, la condición de comunero se adquiere o se pierde con la vecindad misma y es inalienable e imprescriptible; y, además, ninguno de los comuneros puede interesar la división del derecho de pastos.

d) Montes vecinales en mano común y otras comunidades en el ámbito de los Derechos forales

Entre las formas de comunidad en mano común destacan los montes que son propiedad del común de los vecinos de un pueblo, bienes a los que 
si bien, tradicionalmente, se les ha venido atribuyendo naturaleza privada y no comunal, la atribución a los vecinos en cuanto a tales les aproxima en gran medida a los comunales. $\mathrm{Al}$ respecto, la Compilación de Derecho civil foral o especial de Galicia señala que son «indivisibles, inalienables, imprescriptibles e inembargables» y, aunque «el aprovechamiento será preferentemente en común», el Ayuntamiento «si estima conveniente el cultivo agrícola, puede distribuirlos temporalmente en lotes o parcelas que se adjudicarán a los cabezas de familia». Otra modalidad de comunidad indivisible la constituye, también en Galicia, el molino o muiño llamado de herdeiros, destinado a la molturación de granos para consumo familiar y del ganado de sus condueños, y cuyo aprovechamiento se hace por «piezas» en grupos de seis horas, exclusivas de cada heredero y susceptibles de permuta, enajenación o arriendo.

\section{Cotitularidad «pro diviso» sobre objeto diviso}

\section{a) Propiedad dividida por aprovechamientos}

Es muy antiguo el fenómeno de la división de una finca en aprovechamientos, cada uno de ellos atribuído a una persona distinta que lo ejercita no como disfrute de cosa ajena sino como propietario pro parte de la finca y titular exclusivo de aquél. Las ventajas y disfrutes del dominio se distribuyen entre varios sujetos, de tal manera que cada uno no participa en todos los disfrutes por una cuota sino que ejerce en exclusiva una determinada faceta de dicho disfrute, cuya limitación, sin embargo, no le priva de la consideración de dueño del inmueble, si bien en concurrencia con otros. En tales casos, el Tribunal Supremo ha declarado que «el contenido de la propiedad se presenta distribuído entre dos sujetos, de modo que cada uno de ellos tiene una parte de las facultades y pretensiones contenidas en el dominio, pero sin que por esto aparezca uno como propietario y el otro como titular de un derecho limitado sobre cosa ajena, sino que cada uno de los dos titulares es limitado por el derecho del otro, de manera que, desapareciendo el derecho de uno de ellos, el del otro se amplía sin más, para convertirse en propiedad plena otra vez», pese a lo cual «el derecho de los dos propietarios no recae sobre la totalidad e integridad de la cosa, de forma que cada uno pueda gozar de ella y de sus productos en proporción a su respectiva cuota, ya que no existen porciones alícuotas». Constituye el supuesto más frecuente de esta modalidad de propiedad dividida por aprovechamientos el caso en el que uno de los partícipes tiene el derecho a explotar el suelo mediante la 
Aspectos jurídico-privados del fenómeno comunitario...

siembra de cereal, mientras que el otro tiene el derecho exclusivo sobre el arbolado.

La admisión de esta modalidad de propiedad pro diviso, en un sistema tasado o de numerus clausus como el nuestro, se funda en la costumbre y en la jurisprudencia, si bien, verdaderamente, se trata de una forma especial del derecho real de propiedad que parece aproximarse tanto a la copropiedad como a la denominada propiedad horizontal, y también a la medianería con la que tiene de común, frente a la propiedad horizontal, la preponderancia del aspecto comunitario sobre la titularidad individual de los aprovechamientos concretos, respecto de los que su titular, sin duda, tiene todas las facultades del dominio que no lesionen derechos ajenos que puede ejercer con autonomía, pero teniendo, a la vez, en relación al entero objeto de su propiedad pro diviso, y con la misma salvedad, las facultades de un condómino ${ }^{16}$.

\section{b) La medianería}

Habitualmente cuando se habla de medianería suele pensarse en la pared situada entre dos edificios contiguos, común a ambos, que sirve de apoyo a los dos, con el consiguiente ahorro de materiales, trabajo y suelo que hubiera sido necesario emplear si cada uno de los inmuebles tuviera su propio y exclusivo muro. Pero, además, la situación de medianería puede darse en cualquier elemento divisorio de dos fincas: pared, tapia, tabique, cerca, zanja, seto, acequia ..., resultando que, en todos estos casos, hay medianería cuando el elemento divisorio se encuentra situado sobre el terreno de ambas fincas, perteniciendo por mitad a los propietarios de una y otra, aunque no sirva para introducir vigas $u$ otros elementos que sirvan de apoyo al forjado de los pisos de ambos inmuebles. En definitiva, la medianería desempeña en los edificios bien una función de apoyo o bien de simple separación, resultando en este último supuesto la no exclusión de la función de aislamiento del exterior que corresponde a cualquier pared lateral de una casa. Pues bien, de la localización de la regulación de la medianería en nuestro Código civil (arts. 571 a 579) en el título de las servidumbres, del epígrafe de la sección cuarta «de las servidumbres de medianería», de la denominación de servidumbre que recibe esta modalidad en la citada regulación y, específicamente, del contenido del artículo 571 del Código civil, a cuyo tenor, «la servidumbre de medianería se regirá por las disposiciones de este título y por las ordenanzas y usos locales en cuanto no se opongan a él, o no esté prevenido en el mismo", parece deducirse sin duda que la medianería es una servidumbre: un derecho real de cada uno de los medianeros en cosa ajena. 


\section{Carolina del Carmen Castillo Martínez}

Para ello es preciso entender que la pared se encuentra construida no en terreno común a ambos medianeros sino por mitad en el privativo de cada uno de ellos, quedando reservada correlativamente la utilización de la pared a cada medianero hasta la mitad de su espesor, como si la pared estuviera verticalmente dividida por el plano central y cada uno fuera dueño de la mitad edificada sobre su propio terreno, si bien sometida a la carga de contribuir, en cuanto parte integrante de la pared completa, al cerramiento y sustentación del fundo vecino. Sin embargo, la calificación de la medianería como servidumbre parte de un dato imposible, cual es la división fáctica de la pared en mitades no intelectuales sino reales. En efecto, para que exista servidumbre es necesario que, de hecho, exista no una pared, sino dos medias paredes, lo que no sucede en la realidad, en la que la pared constituye un objeto indivisible. Este argumento conduce a la mayoría de la doctrina a considerar que la medianería constituye una situación de comunidad ${ }^{17}$, tesis que se confirma por otros datos: $1^{\circ}$. El hecho de que la ley hable de pertenencia exclusiva de paredes, setos, vallados o zanjas en los supuestos en que existe un signo contrario a la medianería (arts. 573 y 574 del C.C). Si lo contrario a la medianería supone una pertenencia exclusiva, es fácil deducir que aquélla entraña una pertenencia en común, es decir, una comunidad; $2^{\circ}$. El hecho de que en la ley se aluda con reiteración a dueños y propietarios para referirse a los dueños de la medianería (arts. 579, 574, 576, 577, y 578 del C.C); $3^{\circ}$. La circunstancia de que la propia ley califique, de manera expresa y en el contenido de una norma, la situación de medianería como de mancomunidad (art. 579 del C.C).

En todo caso, en la medianería existe una comunidad funcional, pues la pared sirve de apoyo y cerramiento a uno y a otro fundo a la vez, y el hecho de que cada uno pueda introducir las vigas de sus forjados únicamente en la mitad que parece pertenecerle (lo que, por otra parte, elimina la idea de servidumbre, al tratarse de cosa propia), no impide que la pared se mantenga en pie y desarrolle sus funciones en su unidad, y no como dos medias paredes, inexistentes en cuanto tales porque la pared no es divisible, por lo que no pueden constituir objeto de propiedad independiente. Si bien tal funcionalidad aleja a la medianería de los tipos codificados de comunidad y servidumbre: en la comunidad romana se cesa por renuncia a la cuota; en la servidumbre, por abandono del predio sirviente; en la medianería, al medianero, al derribar su propio edificio, no le basta con renunciar a la medianería, sino que debe abonar, además, "todas las reparaciones y obras necesarias para evitar, por aquella vez solamente, los daños que el derribo pueda ocasionar a la pared medianera" (art. 576 del C.C). Por su parte, la jurisprudencia del Tribunal Supremo 
Aspectos jurídico-privados del fenómeno comunitario...

no niega el carácter comunitario de la medianería, aunque lo pretenda hacer compatible con las manifestaciones del Código que la califican como de servidumbre (cfr. SSTS de 16 de marzo de 1888, 26 de noviembre de 1930, y 2 de enero de 1962, entre otras).

\section{Figuras complejas de comunidad y propiedad singular. Comunidad} de ciertos elementos de los edificios unida a la propiedad privativa de sus diferentes pisos o locales: la propiedad horizontal o de casas por pisos. Concepto y naturaleza jurídica de la propiedad horizontal

Sin entrar en detalle y sólo como forzado antecedente, ya en Derecho babilónico ${ }^{18}$ se conoció el precedente de la venta de una porción divisa de una casa. En el Digesto romano, un texto de Papiniano ${ }^{19}$ se refiere a dos casas que tenían un mismo techo y fueron legadas a dos personas diferentes, pero siendo privativas de cada uno ciertas partes. En el mismo Digesto, un fragmento de Ulpiano ${ }^{20}$ explica que si un dueño dividiere un edificio, o una casa, en dos, edificando una pared en medio, en este caso se tienen por dos casas y se les puede, a una y a otra, imponer servidumbre. También en la Edad Media parece conocerse este sistema de propiedad, radicando la causa en la dificultad de vivienda dentro de los recintos amurallados de las ciudades ${ }^{21}$. Así las cosas, la institución pasó a la época moderna y fue recogida en el Código de Napoleón, señalando las legislaciones posteriores tres tendencias: a) Legislaciones que la rechazan (Austria, Alemania, Suiza, si bien se admite en algunos cantones y Estados); b) Legislaciones que la admiten (Francia, España, Italia, Ecuador, Honduras, México, Panamá y Quebec, entre otras); y c) Legislaciones que la silencian. Con posterioridad a la primera Guerra Mundial, se extendió a los territorios austríacos anexionados a Italia. Bégica tuvo su ley en 1924 y Rumanía en 1927.

La propiedad horizontal ${ }^{22}$ es la cualidad jurídica que se predica de un edificio - no necesariamente destinado a uso de vivienda- cuando su destino económico es la división jurídica en pisos o locales susceptibles de aprovechamiento independiente. Dicho régimen jurídico transforma el inmueble a través de la multiplicación de la finca única inicial en una pluralidad de fincas independientes susceptibles de enajenación y gravamen separado, clasifica sus elementos en comunes y privativos, según su destino económico, y dota de individualidad jurídica y económica a las fincas resultantes de la multiplicación, sin que por ello desaparezca la realidad del inmueble inicial considerado en su conjunto. Pero la propiedad horizontal no es el régimen jurídico obligatorio de los inmuebles dividi- 
dos físicamente en pisos y locales. Sobre los mismos puede recaer asimismo una propiedad ordinaria, una copropiedad ordinaria, e igualmente el régimen de propiedad puede ser sustituído por ellas, provocando su extinción. En el régimen de propiedad horizontal, corresponde a cada titular un derecho de propiedad exclusivo sobre su elemento privativo, junto con la copropiedad, con los demás dueños de pisos y locales, de los restantes elementos, pertenencias y servicios comunes. Dicha posición dominical lleva aparejada la participación como miembro en la estructura organizativa del régimen, así como en sus cargas y beneficios. Por otra parte, la propiedad exclusiva sobre la unidad privativa comprende también la del espacio susceptible de aprovechamiento independiente, los elementos arquitectónicos e instalaciones comprendidos dentro de sus límites cuando sirvan exclusivamente a ese propietario y los anejos o espacios privativos que pueden situarse fuera del espacio delimitado, pero que pertenecen de forma discontinua a la finca privativa, según lo establecido en el título constitutivo de la propiedad horizontal.

Con referencia a la naturaleza jurídica de la llamada propiedad horizontal o de casas por pisos, son numerosas las teorías propuestas para explicarla, resultando como posiciones esenciales y enfrentadas, por una parte, la que considera la propiedad horizontal como una forma de comunidad y, por otra, aquélla que la conceptúa como una especie de propiedad exclusiva, si bien cada una de estas dos direcciones, en la actualidad, presenta diversos matices. Junto a las anteriores posturas, algunos autores defienden la posición que considera la propiedad de casas por pisos como una institución de carácter complejo y que reviste una configuración especial ${ }^{23}$. En definitiva, las orientaciones encontradas se reconducen a dos: aquélla que da preferencia a la idea de copropiedad y la que, diversamente, considera principalmente la noción de propiedad exclusiva. La primera de ellas ha tenido notable influencia en nuestra doctrina que, con carácter general, admite la existencia de una forma de comunidad de bienes, si bien se reconoce que se trata de una comunidad especial (voluntaria por su orígen pero forzosa en cuanto a su permanencia), integrada por los titulares de los pisos o departamentos, que ostentan un derecho indiviso e indeterminado sobre las obras fundamentales y de servicio general de la finca, y determinado por localización sobre espacios cúbicos susceptibles de utilizarse independientemente, dentro de los cuales el respectivo titular tiene el ejercicio de una propiedad limitada por los atinentes preceptos legales y por las normas de la comunidad, encaminadas a la salvaguarda, por igual, del interés y los derechos de todos los comuneros ${ }^{24}$. Sin embargo, hay que reconocer que las características con que la regulación más actual reviste el fenómeno de la propiedad de 
Aspectos jurídico-privados del fenómeno comunitario...

casas por pisos casan mal con los principios que norman la comunidad, pues los ordenamientos que establecen el régimen de la propiedad de pisos y departamentos fundamentalmente consagran un principio contrario a la «actio communi dividundo», esencial al instituto de la comunidad de bienes. Por ello, la doctrina actualmente dominante se decanta por la tesis de la propiedad exclusiva sobre los diferentes pisos o locales, bajo un régimen de aprovechamiento conjunto en los elementos comunes ${ }^{25}$.

\section{El régimen jurídico inmobiliario de aprovechamiento por turno}

El denominado time-sharing o multipropiedad surge a partir de los años sesenta como nuevo fenómeno turístico que presenta una alternativa a los modos tradicionales de alojamiento vacacional (arrendamiento de temporada, alojamiento hotelero), a través de la idea de lanzar al mercado la posibilidad de algunas semanas de utilización de apartamentos a un precio sensiblemente inferior al de la adquisición de la propiedad, y con la ventaja de la variedad de destinos ${ }^{26}$. La concepción de la inicialmente llamada «multipropiedad» como producto turístico da una idea de la falta de configuración unívoca. Tras esta nomenclatura se esconden múltiples variantes, cada una de las cuales presenta una problemática diversa. Durante mucho tiempo, la ausencia en nuestro país de una regulación específica del problema propició que, al amparo de la autonomía privada, la idea se plasmara en figuras jurídicas de diverso alcance y problemática. Junto a ello, la caracterización de la llamada multipropiedad como producto turístico introdujo el carácter negociable del derecho adquirido, conviertiéndolo en una fórmula de ahorro e inversión. Además, existía la posibilidad de unir al derecho de disfrute de la vivienda en multipropiedad la de otras pertenecientes a complejos inmobiliarios diferentes, gracias a la afiliación del conjunto inmobiliario turístico de que se tratara a una sociedad de intercambios, lo que venía a complicar la relación contractual. En la actualidad, el aprovechamiento por turno de bienes inmuebles se regula en nuestro país por la Ley 42/1998, de 15 de diciembre, sobre derechos de aprovechamiento por turno de bienes inmuebles de uso turístico y normas tributarias (B.O.E núm. 300, de 16 de diciembre de 1998), en la que se declara que «el derecho de aprovechamiento por turno podrá constituirse como derecho real limitado ...», si bien «en ningún caso podrá vincularse a una cuota indivisa de la propiedad, ni denominarse multipropiedad, ni de cualquier otra manera que contenga la palabra propiedad». Hasta este momento el aprovechamiento por turno había discurrido por cauces típicos, y cuando se optaba por una fórmula de derecho real se trataba prefe- 
rentemente del dominio - cuota a la que se vinculaba un determinado período de tiempo que delimitaba el uso-. Sin embargo, el legislador español, de acuerdo con lo prevenido por los europeos ${ }^{27}$, ha entendido que el dominio no resulta la configuración adecuada para el aprovechamiento por turno. Ciertamente, el hecho de que los titulares estén físicamente alejados del inmueble sería motivo suficiente para rechazar la configuración dominical; además, el vincular al propietario a la adecuada subsistencia del régimen constituído es un motivo adicional. Efectivamente, los titulares del derecho de aprovechamiento por turno que, por definición, viven alejados del inmueble sujeto a ese régimen - lo que no puede afirmarse tan rotundamente de otros conjuntos inmobiliarios, como las urbanizaciones privadas ni, por supuesto, de la propiedad horizontal - no pueden cumplir por sí el conjunto de cargas que pesan sobre la propiedad, ni atender a las exigencias que reclama el aprovechamiento por turno del inmueble. Desde tal consideración, la regulación actual ofrece la posibilidad de configurar el aprovechamiento por turno bien como arrendamiento de temporada de larga duración, bien con carácter de derecho personal u obligacional (no arrendaticio) y también como «multipropiedad».

\section{Notas}

1 ACKerman, B., Liberalismos políticos, en Doxa, Cuadernos de Filosofía del Derecho, $\mathrm{n}^{\mathrm{os}} 17$ y 18, 1995, pp. 25-41. En este mismo ámbito GonZÁlez Altable, Ma P., Liberalismo vs. comunitarismo. John Rawls: una concepción política del bien, en Doxa, Cuadernos de Filosofía del Derecho, $\mathrm{n}^{\text {os }} 17$ y 18, 1995, pp. 117-136, realiza un análisis de la concepción del bien que Rawls elabora como parte integrante de su concepción política de la «justicia como equidad", para pasar luego a examinar hasta qué punto son o no acertadas las críticas comunitaristas dirigidas contra Rawls y contra el neoliberalismo en general, constituyendo su tesis fundamental el que una concepción del liberalismo político como la de Rawls "puede incorporar algunas de las críticas comunitaristas sin renunciar a sus postulados básicos - la defensa de la libertad, la reivindicación de los derechos individuales, la pluralidad y la tolerancia-». Por su parte, PÉREz LLEDÓ, J.A., "Critical legal Studies» y el comunitarismo, en Doxa, Cuadernos de Filosofía del Derecho, ${ }^{o s} 17$ y 18 , 1995, pp. 137-164, considera que el término de comparación con el comunitarismo no es ya el liberalismo sino el movimiento norteamericano «Critical Legal Studies» (CLS), señalando cómo, en su vertiente crítica, ambas corrientes compartirían algunos rasgos comunes al enfrentarse al liberalismo: rechazo al "individualismo atomista" y énfasis en la "construcción social del sujeto moral»; crítica a la solución liberal de las reglas de justicia formales y universales; crítica a las contradicciones del liberalismo ..., si bien en su dimensión constructiva CLS también mostraría las inconsistencias del comunitarismo: criticaría la noción comunitarista de los valores compartidos y de la comunidad como fuente del bien y, sobre todo, desde su fuerte escepticismo metaético, rechazaría los esfuerzos del comunitarismo por ofrecer una reconstrucción filosófica alternativa. 


\section{Aspectos jurídico-privados del fenómeno comunitario...}

2 LAPorta, F. J., Comunitarismo y nacionalismo, en Doxa, Cuadernos de Filosofía del Derecho, $\mathrm{n}^{\text {os }} .17$ y 18,1995 , pp. 53-68.

3 FARRELl, M. D., ¿Hay derechos comunitarios?, en Doxa, Cuadernos de Filosofía del Derecho, $\mathrm{n}^{\text {os }} 17$ y 18,1995 , pp. 69 a 94.

4 Rivera López, E., Las paradojas del comunitarismo, en Doxa, Cuadernos de Filosofía del Derecho, $\mathrm{n}^{\text {os }} 17$ y 18, 1995, pp. 95 a 115.

5 Cfr., por todos, LARENZ, "Zur Lehre der Rechtsgemeinschaft", en los Jherings Jahrbücher 83 (1933), pp. 108 y ss.; BELTRÁN DE HEREDIA, J., Naturaleza jurídica de la copropiedad, en «Revista de Derecho Privado», 1953, pp. 956 y ss., y La comunidad de bienes en el Derecho español, Madrid, 1954, pp. 135-179; VITALE, La natura giuridica della comunione, Roma, 1967; y BRIOSO EscoBAR, E. L., Cuestiones sobre la comunidad de Derecho romano y la facultad de pedir la división, en "Revista de Derecho Notarial», 1980 (núm. 107), pp. 31 y ss.

6 LACRUZ Berdejo, J. L., Elementos de Derecho civil, III, Derechos reales, vol. $2^{\circ}$, Derechos reales limitados. Situaciones de cotitularidad. Bienes inmateriales, con la colaboración de F. de A. Sancho Rebullida, Barcelona, 1980, p. 263. En el mismo sentido, como señala CASTÁn TOBEÑAS, J., Derecho civil español, común y foral, t. II, Derecho de cosas, vol. $1^{\circ}$, Los derechos reales en general. El dominio. La posesión, $14^{\mathrm{a}}$ ed., Madrid, 1992, pp. 458-459, la fórmula empleada por el Código incurre en la inexactitud de suponer que hay propiedad de derechos, siendo así que la propiedad, en su sentido preciso y técnico, no recae más que sobre las cosas corporales; el orígen del error se localiza en que el Código confunde los conceptos de comunidad de bienes y derechos y de copropiedad o condominio, que tienen de común el que ambos implican manifestaciones del fenómeno de la pluralidad de sujetos o titulares de los derechos subjetivos (cotitulari$d a d$ ), pero que difieren por su diverso ámbito, pues la comunidad constituye el género mientras que la copropiedad o condominio constituye la especie, tratándose ésta última de una forma de propiedad que, como tal, sólo puede recaer sobre cosas específicas y determinadas.

7 Al respecto, cfr. BONET RAMÓN, Comentario a la Sentencia de 15 de octubre de 1941, en «Revista de Derecho Privado», 1941, pp. 34 y ss. Esta misma orientación jurisprudencial aparece consolidada en las Sentencias de 10 de marzo de 1949 y 16 de marzo de 1961.

8 Cfr. Aguilera de la Cierva, Actos de administración, de disposición y de conser. vación, Madrid, 1973, y MiQuel GonZÁLeZ, J. M., Comentario al artículo 398 del Código civil, en los "Comentarios al Código Civil y Compilaciones Forales", dirigidos por M. Albaladejo, t.V, vol. $2^{\circ}$, Artículos 392 a 429 del Código civil, Madrid, 1985, pp. 43 y ss

9 Como precisa Lasarte Álvarez, C., Principios de Derecho civil, t. IV, Propiedad y derechos reales (Primera Parte), Madrid, 1996, pp. 184-185, aunque el tenor literal del artículo $393.1^{\circ}$ se refiere exclusivamente a «las cargas», dicho término hay que entenderlo referido a todo tipo de obligaciones que hayan de ser afrontadas por los comuneros, dada su condición de copropietarios, como por ejemplo, los gastos de conservación, administración y reparación; impuestos o tributos; importe de obras realizadas, etc ..

10 Considera Beltrán DE Heredia, J., La comunidad de bienes en el Derecho es. pañol, cit., pp. 341 y ss., que la prórroga debe entenderese autorizada por una sola vez. En un sentido diverso, Miquel GonzÁlez, J. M., Comentario al artículo 398 del Código civil, en los "Comentarios al Código Civil y Compilaciones Forales», cít., p. 464, admite la posibilidad de prórrogas sucesivas, invocando, en apoyo de esta posición, a otros autores como Albaladejo, Lacruz Berdejo y Sancho Rebullida. 
11 Castán ToBeñas, J., Derecho civil español, común y foral, t. II, Derecho de cosas, vol. $1^{\circ}$, cit., pp. $460-461$.

12 Lacruz Berdejo, J. L., Elementos de Derecho civil, III, Derechos reales, vol. $2^{\circ}$, cit., pp. 288-289. En parecidos términos CAPILla RONCERO, F., Derechos reales y Derecho Inmobiliario Registral, coordinado por López López, A., y Montés Penadés, V.L, Valencia, 1993, pp. 377-378.

13 Víd., por todos, GonzÁlez, J., La comunidad hereditaria, en «Revista Crítica de Derecho Inmobiliario", 1931, pp. 174 y ss., y GARCía GRANERO, Cotitularidad y comunidad, en "Revista Crítica de Derecho Inmobiliario», 1946, pp. 618 y ss.

14 Resulta de especial interés señalar que en el ámbito de los Derechos forales o especiales los modelos de comunidad sucesoria y familiar son más variados que en el Código civil, regulándose una variada gama de regímenes, de entre los que es posible destacar los siguientes: la comunidad conyugal continuada; la asociación familiar entre el matrimonio mayor que instituye heredero de sus bienes a un hijo o hija, y éste a su respectivo cónyuge; la asociación o "compañía" entre distintas familias; en Aragón, el consorcio foral sobre bienes heredados que mientras permanecen indivisibles los hace inalienables destinándolos a la herencia familiar ..., entre otros.

15 Sobre este tema puede consultarse, entre otros, MARTín-RETORTILLO, Comunidad de bienes de orígen comunal, en «Revista Crítica de Derecho Inmobiliario», 1961, pp. 733 y ss., y CUADRADO IGLESIAS, Aprovechamiento en común de pastos y leñas, Madrid, 1980.

16 LACRUZ Berdejo, J. L., Elementos de Derecho civil, III, Derechos reales, vol. $2^{\circ}$, cít., pp. 294-295.

17 LACRUZ Berdejo, J. L., Elementos de Derecho civil, III, Derechos reales, vol. $2^{\circ}$, cit., p. 297.

18 Cfr. CUQ, Etudes sur les contrats de l'epoque de la première dynastic babyloniènne en Nouvelle Revue Historique du Droit français et etrangère, París, 1910, p. 458. Igualmente se cita la venta de la planta baja de una casa en la que el vendedor se reservó el piso superior según acta de la época del rey Inmeroum de Sippar, unos 2000 años antes de Jesucristo (víd. Ventura-Traveset y GonzÁlez, A., Derecho de Propiedad Horizontal, $5^{\text {a }}$ ed., Barcelona, 1992, p. 9).

19 D. VIII, 2, de serv. praed. urb. 36.

20 D. VIII, 4, comm. Praed. 6.

21 En este sentido, ordenanzas medievales de las ciudades italianas y francesas como la coutume de Orleáns, entre otras, tratan de esta propiedad; igualmente puede decirse de las de Auxerre, Berry, Bretaña, Clermont, Ferrand, Montargis, Nivernais y París.

22 Actualmente regulada en nuestro ordenamiento por la Ley 49/1960, de 21 de julio, sobre Propiedad Horizontal, reformada por la reciente Ley 8/1999, de 6 de abril, (BOE de 8 de abril de 1999).

23 Cfr., por todos, Reffino Pereyra, La propiedad horizontal, Buenos Aires, 1952, pp. 19-21; BATLLE VÁZQUEZ, La propiedad de casas por pisos, Alcoy, 1973, p. 65; y ROCA SASTRE, R. $\mathrm{M}^{\mathrm{a}}$, Derecho hipotecario, $5^{\mathrm{a}}$ ed., t. II, p. 69 . Al respecto, como señala CASTÁN TOBEÑAS, J., Derecho civil español, común y foral, t. II, Derecho de cosas, vol. $1^{\circ}$, cit., p. 489, tienen razón los autores que configuran la propiedad horizontal como una institución especial e independiente, o como una figura mixta, integrada a la vez por cosas comunes y cosas referidas al dominio particular de los propietarios; pero tales fórmulas poco resuelven prácticamente, pues lo que interesa es calibrar la preponderancia que en ella tengan los elementos de comunidad de bienes o los de propiedad individual exclusiva. 


\section{Aspectos jurídico-privados del fenómeno comunitario...}

24 NAVARro AzPeitia, Naturaleza y regulación de la propiedad de casas divididas por pisos o departamentos, en "Cuestiones de Derecho privado de nuestra posguerra», Colegio Notarial de Barcelona, 1942, p. 50.

25 En España Albaladejo García, M., Derecho civil, t. III, vol. $1^{\circ}$, Parte General y derecho de propiedad, $7^{\mathrm{a}}$ ed., Barcelona, 1991, p. 424, sostiene que "se trata no de una copropiedad total, sino de una figura en la que junto a la propiedad exclusiva de los pisos existe la copropiedad de los elementos comunes", subrayando que las especialidades de la copropiedad sobre los elementos comunes no dan naturaleza excepcional a la figura, pues "cabría decir que, en esencia, no se trata ni más ni menos que de la que por razón de la cosa imponen unas relaciones de vecindad, más estrechas que las corrientes". En semejante sentido se manifiestan EsPín CÁnOVAS, D., Manual de Derecho civil español, $4^{\mathrm{a}}$ ed., vol. II, p. 260, O’Callaghan MuÑoz, X., Compendio de Derecho civil, t. III, Derechos reales e Hipotecario, Madrid, 1985, p. 188-189 y Prats Albentosa, L., Derechos reales y Derecho Inmobiliario Registral, coordinado por López López, A., y Montés Penadés, V.L, cit., pp. 413-414. En Latinoamérica prevalece parecido criterio. Cfr., por todos, BUGEDA, J., La propiedad horizontal, La Habana, 1954, pp. 30 y ss, quien hace suya la tesis defendida por el Profesor de La Habana Agustín Aguirre.

26 Al respecto, cfr., por todos, O’CALlaGHAN MuÑoz, X., Promoción y adquisición de viviendas en régimen de multipropiedad ("Time-sharing»), Madrid, 1987; MARTÍNEZ VÁZQUEZ DE CASTRO, L., La multipropiedad inmobiliaria, Madrid, 1989; BADOSA COLL, F., La multipropietat com a régim juridic inmobiliari, Jornades de Dret Catalá a Tossa, 1998; DE PABLO CONTRERAS, La multipropiedad en el Anteproyecto de Ley de Conjuntos Inmobiliarios (Conjuntos inmobiliarios y multipropiedad), 1993; HERRERO GARCía, Ma J., La multipropiedad, 1992 y PAU PEDRÓN, A., El nuevo derecho real de aprovechamiento por turno. Su configuración y protección en el Anteproyecto de Ley, La Ley, $\mathrm{n}^{\circ} 4243$, 1997, pp. 1 y ss.

27 Vgr. el portugués lo regula como derecho de habitación, el francés como sociedad y el griego como arrendamiento.

\section{Bibliografía}

ACKerman, B., Liberalismos políticos, en Doxa, Cuadernos de Filosofía del Derecho, $\mathrm{n}^{\text {os }}$ 17 y 18,1995 , pp. 25-41.

Aguilera DE la CieRva, Actos de administración, de disposición y de conservación, Madrid, 1973.

Albaladejo García, M. Derecho civil, t. III, vol. $1^{\circ}$, Parte General y derecho de propiedad, $7^{\mathrm{a}}$ ed., Barcelona, 1991.

Badosa Coll, F., La multipropietat com a régim juridic inmobiliari, Jornades de Dret Catalá a Tossa, 1998.

BATLle VÁZQUEZ, La propiedad de casas por pisos, Alcoy, 1973.

BELTRÁN DE HeREDIA, J., Naturaleza jurídica de la copropiedad, en «Revista de Derecho Privado». 1953, pp. 956 y ss., y La comunidad de bienes en el Derecho español, Madrid, 1954.

Bonet RAmón, Comentario a la Sentencia de 15 de octubre de 1941, en "Revista de Derecho Privado", 1941, pp. 34 y ss.

Brioso Escoba, R., E. L., Cuestiones sobre la comunidad de Derecho romano y la facultad de pedir la división, en «Revista de Derecho Notarial», 1980 (n. 107), pp. 31 y ss. 
BUGEDA, J., La propiedad horizontal, La Habana, 1954.

CAPILla Roncero, F., La comunidad de bienes, en "Derechos reales y Derecho Inmobiliario Registral», coordinado por López López, A., y Montés Penadés, V.L, Valencia, 1993.

CASTÁn Tobeñas, J., Derecho civil español, común y foral, t. II, Derecho de cosas, vol. $1^{\circ}$, Los derechos reales en general. El dominio. La posesión, 14 ${ }^{\mathrm{a}}$ ed., Madrid, 1992.

CuAdRAdo Iglesias, Aprovechamiento en común de pastos y leñas, Madrid, 1980.

CUQ, Etudes sur les contrats de l'epoque de la première dynastic babyloniènne en Nouvelle Revue Historique du Droit français et etrangère, París, 1910.

DE PABlo Contreras, P., La multipropiedad en el Anteproyecto de Ley de Conjuntos Inmobiliarios (Conjuntos inmobiliarios y multipropiedad), 1993.

EsPín CÁNovas, D., Manual de Derecho civil español, $4^{\text {a }}$ ed., vol. II.

FARRELL, M. D., ¿ Hay derechos comunitarios?, en Doxa, Cuadernos de Filosofía del Derecho, $\mathrm{n}^{\text {os }} 17$ y 18, 1995, pp. 69 a 94.

García Granero, Cotitularidad y comunidad, en «Revista Crítica de Derecho Inmobiliario", 1946, pp. 618 y ss..

GonzÁlez Altable, Ma P., Liberalismo vs. comunitarismo. John Rawls: una concepción política del bien, en Doxa, Cuadernos de Filosofía del Derecho, $\mathrm{n}^{\text {os }} .17$ y 18, 1995, pp. 117-136.

GonZÁLEZ, J., La comunidad hereditaria, en «Revista Crítica de Derecho Inmobiliario», 1931, pp. 174 y ss.

HERRERO GARCÍA, Ma J., La multipropiedad, 1992.

LACRUZ Berdejo, J. L., Elementos de Derecho civil, III, Derechos reales, vol. $2^{\mathbf{o}}$, Derechos reales limitados. Situaciones de cotitularidad. Bienes inmateriales, con la colaboración de F. de A. Sancho Rebullida, Barcelona, 1980.

LAPORTA, F. J., Comunitarismo y nacionalismo, en Doxa, Cuadernos de Filosofía del Derecho, $\mathrm{n}^{\text {os }} 17$ y 18,1995 , pp. 53-68.

LARENZ, "Zur Lehre der Rechtsgemeinschaft», en los Jherings Jahrbücher 83 (1933), pp. 108 y ss..

Lasarte Álvarez, C., Principios de Derecho civil, t. IV, Propiedad y derechos reales (Primera Parte), Madrid, 1996.

Martín-Retortillo, Comunidad de bienes de orígen comunal, en «Revista Crítica de Derecho Inmobiliario", 1961, pp. 733 y ss.

MARTÍneZ VÁZQUEZ DE CASTRO, L., La multipropiedad inmobiliaria, Madrid, 1989.

Miquel González, J. M., Comentario al artículo 398 del Código civil, en los «Comentarios al Código Civil y Compilaciones Forales", dirigidos por M. Albaladejo, t.v, vol. $2^{\circ}$, Artículos 392 a 429 del Código civil, Madrid, 1985.

NAVARRO AZPEITIA, Naturaleza y regulación de la propiedad de casas divididas por pisos o departamentos, en "Cuestiones de Derecho privado de nuestra posguerra", Colegio Notarial de Barcelona, 1942.

O’Callaghan Muñoz, X., Compendio de Derecho civil, t. III, Derechos reales e Hipotecario, Madrid, 1985 y Promoción y adquisición de viviendas en régimen de multipropiedad («Time-sharing»), Madrid, 1987.

PAU PEDRón, A., El nuevo derecho real de aprovechamiento por turno. Su configuración y protección en el Anteproyecto de Ley, La Ley, n 4243, 1997, pp. 1 y ss.

Prats Albentosa, L., La propiedad horizontal, en «Derechos reales y Derecho Inmobiliario Registral», coordinado por López López, A., y Montés Penadés, V.L, Valencia, 1993. 


\section{Aspectos jurídico-privados del fenómeno comunitario...}

PÉRez Lledó, J. A., «Critical legal Studies» y el comunitarismo, en Doxa, Cuadernos de

Filosofía del Derecho, $\mathrm{n}^{\text {os }} 17$ y 18, 1995, pp. 137-164.

REFFino PEREYRA, La propiedad horizontal, Buenos Aires, 1952, pp. 19-21.

RIVERA LÓPEZ, E., Las paradojas del comunitarismo, en Doxa, Cuadernos de Filosofía del

Derecho, $\mathrm{n}^{\text {os }} 17$ y 18, 1995, pp. 95 a 115.

ROCA SASTRE, R. $\mathrm{M}^{\mathrm{a}}$., Derecho hipotecario, $5^{\mathrm{a}}$ ed., t. II.

Ventura-Traveset y González, A., Derecho de Propiedad Horizontal, $5^{\text {a }}$ ed., Barcelona, 1992.

VitAle, La natura giuridica della comunione, Roma, 1967. 